\title{
Effect of cold stress on physicochemical characteristics and biological activity of equine chorionic gonadotropin
}

\author{
R.H. Alvarez ${ }^{1,4}$, F.L.N. Natal ${ }^{1}$, B.E. Almeida ${ }^{2}$, J.E. Oliveira ${ }^{2}$, P. Bartolini ${ }^{2}$ A.J.F. Melo ${ }^{1}$, K.M.R. Duarte ${ }^{3}$, \\ M.T.C. Ribela ${ }^{2}$
}

${ }^{1}$ Agency for Agribusiness Technology of São Paulo, Piracicaba, SP, Brazil.

${ }^{2}$ Biotechnology Department, IPEN-CNEN, Cidade Universitária, São Paulo SP, Brazil.

${ }^{3}$ Institute of Animal Science, Nova Odessa SP, Brazil.

\begin{abstract}
The purpose of this study was to evaluate if freezing-thawing and cooling processes affect the structural properties and biological activity of commercial equine chorionic gonadotropin (eCG). First, the structure profile of diluted eCG underwent none, one or three cycles of freezing-thawing was analysed by reverse phase high-performance liquid chromatography (RP-HPLC). In a second experiment, groups of prepuberal rats were treated with sterile water for injection USP or eCG that underwent none, one or three cycles of freezing-thawing to assess the increase of ovarian weigh. Finally, groups of prepubertal gilts were treated with diluted eCG immediately after reconstitution (T1), after refrigeration for six months (T2) and after freezing and subsequently thawing for one (T3) or three (T4) cycles. The control group (T5) received sterile water for injection USP without eCG. Ovulation was induced with human chorionic gonadotropin (hCG), administered $72 \mathrm{~h}$ after the eCG. Gilts were slaughtered five days after the hCG injection and ovaries were recovered and analysed for the presence of corpora lutea. Data were analysed by ANOVA and Fisher's exact tests. In the analyses by RP-HPLC, the retention times of cold stressed eCG were similar to unstressed control. The mean ovarian weight of rats treated with cold stressed and unstressed eCG was statistically higher than water control $(\mathrm{P}<0.05)$. Lastly, significantly more gilts ovulated in groups $\mathrm{T} 1, \mathrm{~T} 2, \mathrm{~T} 3$ and $\mathrm{T} 4$ than in the control T5 $(\mathrm{P}<0.05)$. It was concluded that freezingthawing, as well as cooling over a period of up to six months, did not significantly change the structural properties or biological activity of eCG.
\end{abstract}

Keywords: bioassay, eCG, prepuberal gilts, protein stability, RP-HPLC.

\section{Introduction}

Proteins are complex macromolecules that are polymers of the 20 amino acids connected through peptide bonds. This primary sequence is then folded into the secondary, tertiary and quaternary structure required for function (Nearhi, 2013). Equine chorionic gonadotropin (eCG), originally known as pregnant mare serum gonadotropin (PMSG), belongs to the family of glycoprotein hormones (Murphy and Martinuk, 1991; Murphy, 2012). It is produced by trophoblast cells (endometrial cups) between 36 and 120 days of pregnancy (Allen and Moor, 1972; Murphy and Martinuk, 1991) and plays an important role in the maintenance of early gestation in mares (Allen and Moor, 1972). The eCG is composed of two heterogeneous subunits ( $\alpha$ and $\beta$ ) joined by noncovalent bounds, both subunits being necessary for expression of their biological activity (Papkoff, 1974). The high acid sialic content of eCG is responsible for the long half-life of eCG in the systemic circulation, as it contribute to its negative ionic nature and therefore hinder hepatic metabolism and glomerular filtration (Combarnous et al., 1981; Martinuk et al., 1991). Additionally, eCG has the unique ability to emulate follicle stimulating hormone (FSH) and luteinizing hormone (LH) activity in species other than horses (Martinuk et al., 1991). For this reason, eCG has been broadly used to induce ovarian stimulation in domestic species in order to advance puberty, induce superovulation, reverse anestrus and, more recently, synchronize estrus for timed artificial insemination (Murphy, 2012; Bó and Baruselli, 2014).

Typically, commercial eCG preparations are manufactured after fractional precipitation, removal of impurities, $\mathrm{pH}$ adjustment and final precipitation in the presence of increasing concentrations of acetone or alcohol (Lunenfeld, 2004). Additionally, antiseptic and antifungal agents, such as thimerosal, and other excipients (mannitol, lactose, disodium hydrogen phosphate 2aq) are added to protect, support or enhance the stability of eCG before storing it as a freeze-dried (lyophilized) substance.

Since cooling and freezing of proteins lead to the development of stresses, such as solute concentration and ice formation, that can impact the stability of proteins (Pikal-Cleland et al., 2000), the manufacturing laboratories do not recommend freezing or refrigerated storing of the reconstituted eCG, at risk of losing effectiveness. However, it is known that some proteins such as $\operatorname{IgG}$ can be refrigerated or frozen for long periods of time without significant loss of activity (Argüello et al., 2003). Furthermore, glycoprotein hormones such as pituitary FSH and LH (Reyna et al., 2001) or recombinant thyroid stimulating hormone (TSH; Lin et al., 2010) had no consistent or predictable alteration when subjected to repeated freezing-thawing cycles or long periods of refrigerated storage.

Currently, there are no published studies using reverse phase high-performance liquid chromatography 
(RP-HPLC) assays to examine eCG stability after frozen storage. The aim of this study was to determine if repeated freezing-thawing cycles as well as differences in storage temperatures negatively affect the structural or biological activity of reconstituted eCG.

\section{Materials and Methods}

All the procedures for maintenance and euthanasia of animals followed international standards for use of animals and were approved by the Ethics Committee of Animal Science Institute/APTA (proc. IZ-159).

Source and conditions of cold stressed eCG preparations

The eCG commercial preparation Novormon ${ }^{\circledR}$ (Batch number 034/11; MSD Animal health, São Paulo, Brazil) was purchased at a local veterinary pharmacy, while the reference standard World Health Organization (WHO) International Standard of eCG (code 62/001) was purchased from the National Institute for Biological Standards and Control (NIBSC, South Mimms, UK). Samples of commercial and international standard eCG were diluted in sterile water for injection USP and submitted to one (T1) or three (T2) freezing-thawing cycles. A cycle consisted of freezing diluted eCG at $80^{\circ} \mathrm{C}$ for one hour and then thawing it in water at $37^{\circ} \mathrm{C}$ until ice disappearance. Reconstituted eCG not stressed by cold (T3), and denatured eCG submitted to $100^{\circ} \mathrm{C} / 15$ min (T4), were used as controls.

\section{Physicochemical evaluation of eCG}

In experiment 1 , the effect of freezing-thawing process on eCG structure was analysed by RP-HPLC, according to methodology described previously to determine the physicochemical profile of hLH, hFSH and hCG (Almeida et al., 2010, 2011). Briefly, samples of eCG (WHO) treated previously as described in Section 2.1 were analysed in a Shimadzu Model SCL10AHPLC apparatus with a SPD-10AV UV detector and a C4-Grace Vydac (Separation group, Hesperia, CA, USA) 214 TP 54 column $(25 \mathrm{~cm} \times 4.6 \mathrm{~mm}$ I.D., pore diameter of $300 \AA$ and particle diameter of $5 \mu \mathrm{m}$ ), coupled to a Grace Vydac (Separation group, Hesperia, CA, USA) 214 FSK 54 guard pre-column $(1 \mathrm{~cm} \times 4.6$ $\mathrm{mm}$ ID). Solutions A (0.05 M ammonium phosphate $\mathrm{pH}$ 8.6) and B (acetonitrile) were utilized, carrying out a 40 min gradient using a concentration of $\mathrm{B}$ in $\mathrm{A}$ from 15 to $60 \%$ and a $10 \mathrm{~min}$ isocratic mode with $60 \% \mathrm{~B}$. The sample volume was $100 \mu \mathrm{l}$ and the running time was 50 min, with a flow rate of $0.5 \mathrm{ml} / \mathrm{min}$. The column temperature was maintained at $25^{\circ} \mathrm{C}$ and detection was by UV absorbance at $220 \mathrm{~nm}$. The precision of this specific quantitative methodology, based on direct eCG determinations, provided CVs of 1.3 and $3.1 \%$ for intraand inter-assay, respectively.

\section{Rat biological assay}

In experiment 2, the effects on biological activity of different eCG treatments were assessed using the in vivo method of Cole and Erway (1941) recognized by the International Pharmacopoeia. Briefly, Wistar albino rats (Rattus norvegicus), 21 to 23 day old, weighing $70.5 \pm 3.2 \mathrm{~g}$ were purchased from the Multidisciplinary Center for Biological Investigation of Laboratory Animal Science (CEMIB-UNICAMP, Campinas, Brazil). Animals were housed in a temperature-controlled room $\left(24 \pm 2^{\circ} \mathrm{C}\right)$ in clean polypropylene cages under standard conditions and were offered a standard pelleted diet and water $a d$ libitum. Rats were randomly separated into five groups of six animals, and each group received intraperitoneal (IP) injections of one of the four treatments (T1, T2, T3 and T4 described in Section 2.1) of eCG (Novormon ${ }^{\circledR}$ ) at $10 \mathrm{IU} /$ animal, while the fifth group received sterile water for injection USP without eCG (T5). Forty-eight hours after the eCG or water injection, the rats were euthanized via IP injection of a mixture of $80 \mathrm{mg}$ ketamine (Quetamina, Vetnil Ind. e Com. de Produtos Veterinários Ltda, Louveira, SP, Brazil) with $15 \mathrm{mg}$ xylazine (Dorcipec, Valeé, Produtos Veterinários, Montes Claros, MG, Brazil) and the genital tract was surgically removed. The ovaries were weighed separately on an analytical scale (Shimadzu, model AT, precision: $0.1 \mathrm{mg}$ ) and the combined mass of both ovaries of each animal was taken into consideration, as recommended by the international Pharmacopoeia for the evaluation of biological response to eCG.

\section{Gilt biological assay}

Experiment 3 was conducted at the Tanquinho's Swine Research Center of the Agency for Agribusiness Technology of São Paulo (Piracicaba, SP, Brazil) in the months of January to March of 2013. Crossbred gilts of the Pen Ar Lan lineage P76 males and Näima females (Pen Ar Lan, Piracicaba SP, Brazil) were randomly allotted to individual pens located in the same area of the building. After an adaptation period of about 35 days, five-month old gilts $(\mathrm{n}=30)$ with an average body weight of $86.0 \pm 9.2 \mathrm{~kg}$ were randomly distributed into five groups of six animals each and received intramuscular (IM) injections of $750 \mathrm{IU}$ of eCG $\left(\right.$ Novormon $^{\circledR}$ ) as follow: T1) eCG applied immediately after reconstitution; $\mathrm{T} 2$ ) recontituted $\mathrm{eCG}$ preserved refrigerated (at $4^{\circ} \mathrm{C}$ ) for six months; T3) recontituted eCG subbmited to one freezing-thawing cycle; T4) recontituted eCG subbmited to three freezing-thawing cycles; T5) control group injected with sterile water without eCG. Ovulation was induced with an IM injection of 500 IU human chorionic gonadotropin (hCG; Chorulon, MSD Animal Health, São Paulo, Brazil), administered $72 \mathrm{~h}$ after eCG or water injections. Gilts were slaughtered five days after the hCG injection and ovaries were recovered and weigthed. The corpora lutea (CL) of each ovary were counted and ovulation was inferred if CL were present in at least one of the ovaries.

\section{Statistical analysis}

Data was analysed using the Real Statistics 
Resource Pack software (Zaiontz, 2015).

The normality of the data was previously verified using the Shapiro-Wilk Original Test. The ovarian weight of female rats was not distributed normally and needed to be $\log$ transformed to create symmetry. The one-way analysis of variance (ANOVA) F-test was used for multiple comparisons, followed by Student-Newman-Keuls pairwise comparisons. Categorical variable (ovulation in response to hCG) was analysed using the Chi-square test and Fisher's exact test for pairwise comparisons. Results were considered significantly different if $\mathrm{P}<0.05$.
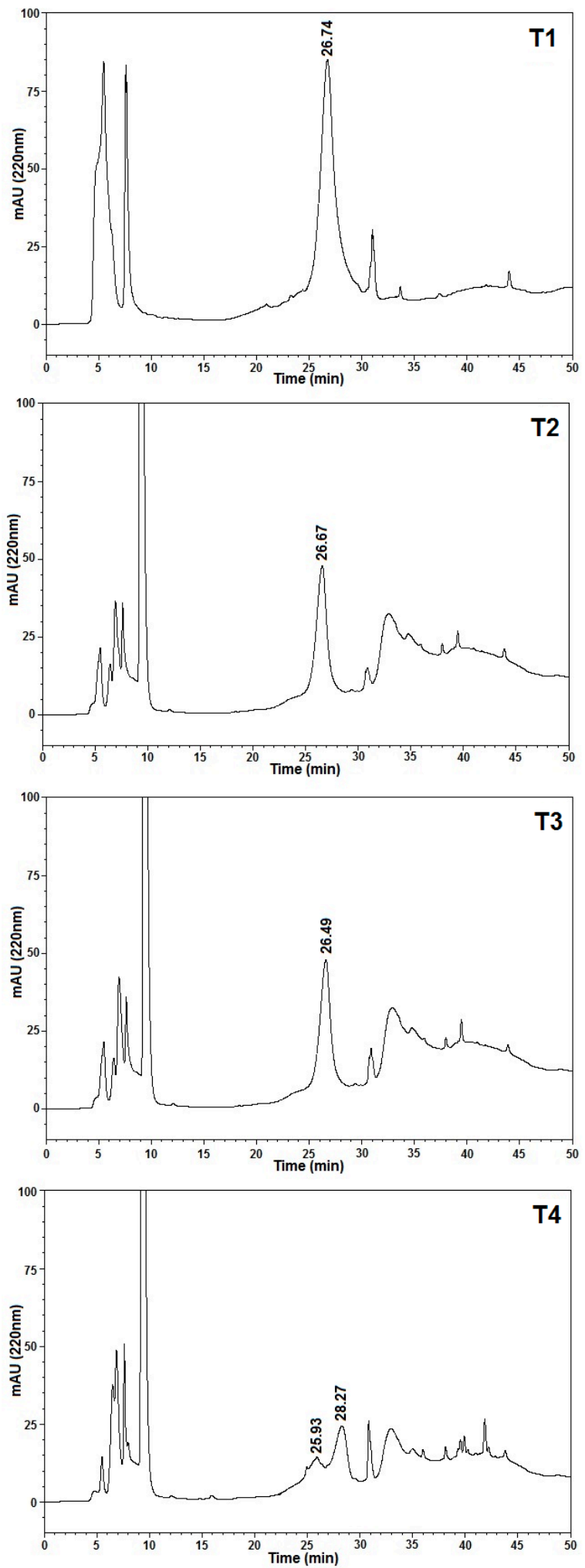

\section{Results}

\section{Physicochemical assay}

The result of the chromatographic profile (RPHPLC) of the eCG samples undergoing different treatments is shown in Fig. 1. Cold stressed (T1 and T2) and intact unstressed (T3) treatments showed an isolated major peak with practically identical retention times (average of $26.6 \mathrm{~min}$ ). Denatured eCG (T4), however, had varying peaks, two of which, at 25.9 and $28.3 \mathrm{~min}$, seem to correspond to the $\alpha$ and $\beta$ dissociated subunits (Fig. 1).

Figure 1. RP-HPLC physicochemical profile of diluted eCG (WHO). Samples were analysed immediately after reconsitution (T1); after freezing-thawing one (T2) or three (T3) times, and after heating to $100^{\circ} \mathrm{C} / 15 \mathrm{~min}$ (T4). 
Rat assay

Results of the ovarian response in rats injected with the different eCG treatments are shown in Fig. 2. The weight of the ovaries of animals in treatment groups $\mathrm{T} 1(38.1 \pm 6.6 \mathrm{mg}), \mathrm{T} 2$ $(38.9 \pm 4.1 \mathrm{mg})$ and $\mathrm{T} 3(43.8 \pm 5.0 \mathrm{mg})$ was similar and significantly higher than that of the controls T4 $(23.6 \pm 0.8 \mathrm{mg})$ and T5 $(21.5 \pm 1.0 \mathrm{mg})$ groups $(\mathrm{P}<0.05)$.

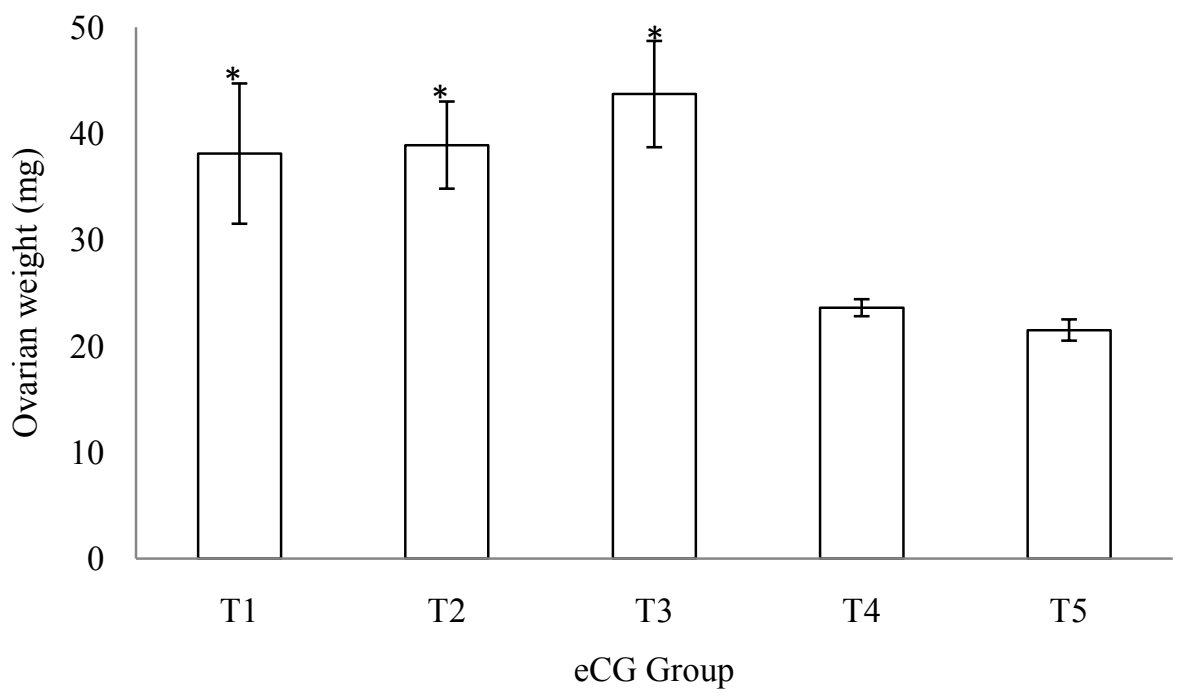

Figure 2. The effect of cold and heat stress of commercial eCG (10 IU) on ovarian weight from prepubertal rats. Bars represent mean of data collected from 6 animals, and error bars, SEM. An asterisk indicates significant differences from the control group (Student-Newman-Keuls Test, $\mathrm{P}<0.05$ ). Reconstituted eCG was applied: immediately after dilution in sterile water (T1); after one (T2) or three (T3) freezing-thawing cycles, and after heating to $100^{\circ} \mathrm{C} / 15 \mathrm{~min}$ (T4). Control group (T5) was injected only with sterile water.

\section{Gilt assay}

The results of the ovarian response of the treated animals are described in Table 1 . More gilts of T1 (5/6), T2 (6/6), T3 (4/6) and T4 (6/6) treatments ovulated following the hCG injection than the control T5 $(0 / 6$; $\mathrm{P}<0.05)$. The average number of ovulations of gilts treated with the different eCG treatments ranged from
$6.3 \pm 2.5(\mathrm{~T} 3)$ to $14.0 \pm 2.8(\mathrm{~T} 2 ; \mathrm{P}>0.05)$ and was significantly different than the control T5 $(0 \pm 0, \mathrm{P}<0.05)$. Ovaries from control group had follicles smaller than two millimeters with no evidence of ovulation.

Ovaries were heavier in eCG treated gilts $(\mathrm{T} 1=5.7 \pm 0.7 ; \mathrm{T} 2=6.5 \pm 1.1 ; \mathrm{T} 3=5.0 \pm 0.3 ; \mathrm{T} 4=$ $7.2 \pm 0.9)$ than the control $(\mathrm{T} 5=3.4 \pm 0.2 ; \mathrm{P}<0.05)$, but there was no difference between eCG treated groups.

Table 1. Ovarian response of prepubertal gilts treated with commercial eCG diluted in sterile water (T1); eCG diluted and keep refrigerated at $4^{\circ} \mathrm{C}$ during 6 months (T2); eCG submitted to one (T3) or three (T4) freezingthawing cycles; and just sterile water without eCG (T5). Ovulation was induced with hCG administered $72 \mathrm{~h}$ after eCG or water injection.

\begin{tabular}{lccc}
\hline eCG treatment & Ovulating gilts $(\%)$ & Ovulation rate $(\mathrm{CL})^{*}$ & ${\text { Ovarian weight }(\mathrm{g})^{*}}^{\mathrm{a}}$ \\
\hline T1 & $5 / 6(83.3)^{\mathrm{a}}$ & $8.2 \pm 2.2^{\mathrm{a}}$ & $5.7 \pm 0.7^{\mathrm{a}}$ \\
T2 & $6 / 6(100)^{\mathrm{a}}$ & $14.0 \pm 2.8^{\mathrm{a}}$ & $6.5 \pm 1.1^{\mathrm{a}}$ \\
T3 & $4 / 6(66.7)^{\mathrm{a}}$ & $6.3 \pm 2.5^{\mathrm{a}}$ & $5.0 \pm 0.3^{\mathrm{a}}$ \\
T4 & $6 / 6(100)^{\mathrm{a}}$ & $13.6 \pm 3.8^{\mathrm{a}}$ & $7.2 \pm 0.9^{\mathrm{a}}$ \\
T5 & $0 / 6(0)^{\mathrm{b}}$ & $0.0 \pm 0.0^{\mathrm{b}}$ & $3.4 \pm 0.2^{\mathrm{b}}$
\end{tabular}

Different superscripts $^{\mathrm{a}, \mathrm{b}}$ in columns indicate significant difference from the control group $(\mathrm{P}<0.05)$. *Mean \pm SEM.

\section{Discussion}

The conformation (overall global fold or threedimensional structure) of a protein is important for maintaining biological activity and stability during longterm storage. It can also impact the safety profile and biological consequences of bio-therapeutics (Nearhi, 2013). The stability of protein conformations can be probed by exposing the protein to external perturbations such as high pressure, acidic $\mathrm{pH}$, chemical denaturants or high and low temperatures (Cho et al., 2012). Protein denaturation involves a change in the protein structure (generally an unfolding) with the subsequent loss of activity. Heat denaturation and loss of biological activity have been linked to the breakup of the 2-Dspanning water network around protein molecules, due to increasing hydrogen bond breakage with higher temperatures (Koizumi et al., 2007). As shown in Fig. 1, 
a temperature of $100^{\circ} \mathrm{C}$ over 15 min resulted in the disruption of folded configurations of eCG, leading to separate subunits, which have no known biologic activity. Indeed, it is the formation of the heterodimer that provides the hormonal activity through attachment of the carbohydrate moieties, and the extent of glycosylation, especially sialylation, that conveys the spectrum of differences in charge, bioactivities, and elimination half-lives (Ulloa-Aguirre et al., 1988). Protein unfolding at higher temperatures is easily understood but the widespread existence of protein unfolding at low temperatures is surprising, particularly as it is unexpectedly accompanied by a decrease in entropy (Tsai et al., 2002). Although the exact mechanism of protein denaturation by cold is not fully understood, it is known that protein degradation during freezing is attributed to ice formation which causes a tremendous increase of electrolyte components, resulting in large $\mathrm{pH}$ shifts which can destabilize the protein (Bhatnagar et al., 2007). However, repeated freezing and thawing of dog serum did not affect the concentration of thyroxin, cortisol, or insulin (Reimers et al., 1982). Other studies have also noted that the level of biochemical constituents, including glucose and enzymes of transferase, kinase and phosphatase groups, in rat serum (Kale et al, 2012) or dog plasma (Reynolds et al., 2006), was relatively stable after up to three cycles of repeated freezing and thawing. Also, Livesey et al. (1980) demonstrated that, with the exception of a decrease in insulin levels, human plasma gonadotropins (LH, FSH, TSH, growth hormone, and prolactin) were stable over five freezing-thawing cycles. Finally, repeated freezing and thawing, and short-term refrigeration of an analogue of luteinizing hormone releasing hormone (D-trp6-pro9-NEt-LHRH [LHRHa]) did not have any apparent effect on the HPLC profile or biological activity and the authors concluded that the results obtained with the HPLC method correlated well with the results from in vivo (Winterer et al., 1983) and in vitro (Shi et al., 1984) bioassays.

The effect of storage temperature and duration on the stability and biological potency of eCG samples is less well documented. According to the manufacturer's instructions, lyophilized eCG must be stored in the dark at 2 to $8^{\circ} \mathrm{C}$. Once reconstituted in water for injection, the solution should be used immediately or within a few hours, and the unused portion of the vial must be discarded. However, to our knowledge, studies dealing with the effects of temperature and duration of storage on biological potency of reconstituted eCG are still limited. Results of the present study indicated that freezing-thawing, or cooling over a period of 6 months, did not significantly change the structure or biological activity of eCG. Similar to our results, Lin et al. (2010) found that recombinant human TSH kept at $4,-11$ and $-60^{\circ} \mathrm{C}$ maintained good biological potency for more than 6 months of storage when tested in vitro, indicating that biological activity is very stable. Curiously, in this study, cold stressed TSH tended to show an increase in bioactivity in comparison with the control.

Probably, the deleterious effect of storage time on eCG follows the pattern of the gonadotropin FSH, which shows a slight decrease $(2.8 \%)$ in immunoreactivity after a week of storage at 4 or $-20^{\circ} \mathrm{C}$ and about a $40 \%$ decrease after 64 weeks (Scriver et al., 2010). One weakness of our study is that we did not compare the results with a reference standard curve of dose-response in each assay; thus, we cannot quantify the eventual loss of biological potency. Indeed, although comparison of ovarian response to cold stressed and unstressed eCG in rat and gilt assays are statistically significant as noted in Fig. 2 and Table 1, the variability in ovarian response does not completely exclude the possibility that there may be some loss of bioactivity. Despite this limitation, this study can serve as a pilot for establishing variables for future research on this topic.

In conclusion, our data indicate that the physicochemical structure and biological activity of eCG is remarkably stable under usual cold or freezing storage conditions. The data suggest that repeated freezing-thawing or refrigeration at $4^{\circ} \mathrm{C}$ for several months does not result in complete loss of biological activity. Therefore, the use of stored eCG after dilution may result in financial savings in situations where less than a full ampoule is an appropriate dose.

\section{Acknowledgments}

The authors wish to thank the staff at the Swine Research Centre (UPD-Tanquinho), Maria de Lourdes Oliveira and Isabel Cristina Rovay Manarin for their assistance in executing Exp. 3. This study was funded by FAPESP (grant 2011/13096-0).

\section{References}

Allen WR, Moor RM. 1972. The origin of the equine endometrial cups. I. Production of PMSG by fetal trophoblast cells. J Reprod Fertil, 29:313-316.

Almeida BE, Oliveira JE, Carvalho CM, Dalmora SL, Bartolini P. Ribela MTCP. 2010. Analysis of human luteinizing hormone and human chorionic gonadotropin preparations of different origins by reversed-phase high-performance liquid chromatography. J Pharm Biomed Anal, 53:90-97.

Almeida BE, Oliveira JE, Damiani R, Dalmora SL, Bartolini P, Ribela MTCP. 2011. A pilot study on potency determination of human follicle-stimulating hormone: a comparison between reversed-phase highperformance liquid chromatography method and the in vivo bioassay. J Pharm Biomed Anal, 54:681-686.

Argüello A, Castro N, Capote J, Ginés R, Acosta F, López JL. 2003. Effects of refrigeration, freezingthawing and pasteurization on IgG goat colostrum preservation. Small Rumin Res, 48:135-139.

Bhatnagar BS, Bogner RH, Pikal MJ. 2007. Protein stability during freezing: separation of stresses and mechanisms of protein stabilization. Pharm Dev Technol, 12:505-523

Bó GA, Baruselli PS. 2014. Synchronization of ovulation and fixed-time artificial insemination in beef cattle. Animal, 8:144-150.

Cho MK, Xiang SQ, Kim HY, Becker S, 
Zweckstetter M. 2012. Cold-induced changes in the protein ubiquitin. PLoS One, 7(6):e37270.

Cole H, Erway J. 1941. 48-hour assay test for equine gonadotropin with results expressed in international units. Endocrinology, 29:514-519.

Combarnous Y, Salesse R, Garnier J. 1981. Physicochemical properties of pregnant mare serum gonadotropin. Biochim Biophys Acta, 667:267-276.

Kale VP, Patel SG, Gunjal PS, Wakchaure SU, Sundar RS, Ranvir RK, Jain MR. 2012. Effect of repeated freezing and thawing on 18 clinical chemistry analytes in rat serum. J Am Assoc Lab Anim Sci, 51:475478.

Koizumi M, Hirai H, Onai T, Inoue $K$, Hirai $M$. 2007. Collapse of the hydration shell of a protein prior to thermal unfolding. J Appl Crystallogr, 40:s175-s178.

Lin R, Hogen V, Cannon S, Marion KM, Fenton MS, Hershman JM. 2010. Stability of recombinant human thyrotropin potency based on bioassay in FRTL-5 cells. Thyroid, 20:1139-1143.

Livesey JH, Hodgkinson SC, Roud HR, Donald RA. 1980. Effect of time, temperature and freezing on the stability of immunoreactive $\mathrm{LH}, \mathrm{FSH}, \mathrm{TSH}$, growth hormone, prolactin and insulin in plasma. Biochemistry, 13:151-155.

Lunenfeld B. 2004. Historical perspectives in gonadotrophin therapy. Hum Reprod Update,10:453467.

Martinuk S, Manning A, Black W, Murphy B. 1991. Effects of carbohydrates on the pharmacokinetics and biological activity of equine chorionic gonadotrophin in vivo. Biol Reprod, 45:598-604.

Murphy BD, Martinuk S. 1991. Equine chorionic gonadotropin. Endocr Rev, 12:27-44.

Murphy BD. 2012. Equine chorionic gonadotropin: an enigmatic but essential tool. Anim Reprod, 9:223-230.

Nearhi LO. 2013. Biophysics for therapeutic protein development. In: Nearhi LO (Ed.). Biophysics for the Life Sciences 4. New York, NY: Springer Science+ Business Media. 293 pp.

Papkoff H. 1974. Chemical and biological properties of the subunits of pregnant mare serum gonadotropin. Biochem Biophys Res Commun, 58:397-404.

Pikal-Cleland KA , Rodríguez-Hornedo N, Amidon
GL, Carpenter JF. 2000. Protein denaturation during freezing and thawing in phosphate buffer systems: monomeric and tetrameric b-galactosidase. Arch Biochem Biophys, 384:398-406.

Reimers TJ, McCann JP, Cowan RG, Concannon PW. 1982. Effects of storage, hemolysis, and freezing and thawing, on concentrations of thyroxine, cortisol, and insulin in blood samples. Proc Soc Exp Biol Med, 170:509-516.

Reyna R, Traynor KD, Hines G, Boots LR, Azziz R. 2001. Repeated freezing and thawing does not generally alter assay results for several commonly studied reproductive hormones. Fertil Steril, 76:823-825.

Reynolds B, Taillade B, Médaille C, Palenché F, Trumel C, Lefebvre HP. 2006. Effect of repeated freeze-thaw cycles on routine plasma biochemical constituents in canine plasma. Vet Clin Pathol, 35:339. 340 .

Scriver J, Baker VL, Young SL, Behr B, Pastore LM. 2010. Inter-laboratory validation of the measurement of follicle stimulating hormone (FSH) after various lengths of frozen storage. Reprod Biol Endocrinol, 8:145. doi:10.1186/1477-7827-8-145.

Shi YF, Sherins RJ, Brightwell D, Gallelli JF, Chatterji DC. 1984. Long-term stability of aqueous solutions of luteinizing hormone-releasing hormone assessed by an in vitro bioassay and liquid chromatography. J Pharm Sci, 73:819-821.

Tsai CJ, Maizel JV, Nussinov R. 2002. The hydrophobic effect: a new insight from cold denaturation and a two-state water structure. Crit Rev Biochem Mol Biol, 37:55-69.

Ulloa-Aguirre A, Espinoza R, Damian-Matsumura P, Chappel SC. 1988. Immunological and biological potencies of the different molecular species of gonadotrophins. Hum Reprod, 3:491-501.

Winterer J, Chatterji D, Comite F, Decker MH, Loriaux DL, Gallelli JF, Cutler GB Jr. 1983. Thermal stability of a long-acting analogue of luteinizing hormone releasing hormone (D-trp6-pro9-NEt-LHRH). Contraception, 27:195-200.

Zaiontz C. 2015. The Real Statistics Resource Pack software, Release 4.3. Available on: www.realstatistics.com. 